Environment Conservation Journal 14(3)61-68, 2013

ISSN 0972-3099 (Print) 2278-5124 (Online)

Abstracted and Indexed

\title{
Bio-degradation of 40 micron plastic bags by Aspergillus niger and optimization of pre-treatment methods
}

\author{
Sagar Kittur $^{1} \bowtie$, Namrata Patil ${ }^{1}$, Shruti Kammar ${ }^{1}$, V. G. Shanmuga Priya ${ }^{1} \&$ D. N. Sastry ${ }^{2}$ \\ Received: 24.08.2013 \\ Revised: 03.10.2013 \\ Accepted: 31.10.2013
}

\begin{abstract}
Lack of degradability and the closing of landfill sites as well as growing water and land pollution problems have led to concern about plastics. Among the various types of plastics, the most extensively used type is polyethylene bags. A survey on 40 micron polyethylene bags was done by obtaining the information from the City corporation office, Belgaum, Karnataka, India on the amount of plastic waste generated in the city. Polyethylene bags having a thickness less than 40 micron are not recycled, thus have to be degraded. In this work, Aspergillus niger is been employed to degrade the 40 micron plastic. Various pre-treatment methods are used which include UV, nitric acid, thermal and UV + nitric acid treatments to effectively degrade the plastic. Different media having pre treated plastic as the carbon source are tested for the degradation of plastic along with the growth of the fungi. Incubation period was taken as 15 and 30 days. Optimization of pre-treatment methods was done to improve the degradation efficiency. Various analysis methods such as FTIR spectroscopy and dry-weight analysis were done to confirm the degradation of plastic.
\end{abstract}

Keywords: 40 micron polyethylene bags, Aspergillus niger, bio-degradation, pre-treatment optimization, nitric acid, FTIR, UV

\section{Introduction}

Plastics are man-made long chain polymeric molecules (Scott, 1990). A plastic material is any of a wide range of synthetic or semi-synthetic organic solids that are mouldable.Plastics are typically organic polymers of high molecular mass, but they often contain other substances.They are usually synthetic,most commonly derived from petrochemicals, but many are partially natural. The word plastic is derived from the Greek word (plastikos) meaning capable of being shaped or moulded, from word (plastos) meaning moulded (Joel, 1995). It refers to their malleability or plasticity during manufacture, that allows them to be cast, pressed or extruded into a variety of shapes- such as films, fibers, tubes, bottles, boxes and much more. The vast majority of these polymers are based on chains of carbon atoms alone or with oxygen, sulphur or nitrogen as well. The properties of plastics are defined chiefly by the

\footnotetext{
Author's Address

${ }^{1}$ Dept of Biotechnology, Dr. M.S.Sheshgiri College of Engineering and Technology, Udyambag Belgaum, Karnataka, India

${ }^{2}$ Dept of Pharmaceutical BT, KLE University's Pharma College, Belgaum, Karnataka, India

Email: kittursm@gmail.com
}

organic chemistry of the polymer such as hardness, density, and resistance to heat, organic solvents, oxidation, and ionizing radiation. Aspergillus niger or A.niger is a fungus and one of the most common species of the genus Aspergillus.In addition to its application in industry for production of citric acid, amylases, lipases, cellulases, xylanases and proteases, it is also used in waste management and bio-transformations. The fungi are most commonly found in mesophilic environments such as decaying vegetation or soil and plants.

\section{Survey on 40 micron plastics}

\section{Reports Belgaum city corporation office}

Facts in Belgaum: (Data obtained from city corporation office, Belgaum)

Geographical area of urban Belgaum is $95 \mathrm{~km}^{2}$ (37 sq mi) having a population of 488,292.

On an average $9.466 \mathrm{~kg}$ /day of plastic waste is generated from each area. (Table 1)

\section{Material and methods}

A) Microorganism and media: Aspergillus niger bearing NCIM no 1025 was ordered from NCIM

Copyright by ASEA 
NCL Pune. Media used for sub-culturing was PDA (Potato dextrose agar) of Hi Media Company.

B) Collection and cleaning of plastic: 40 micron polyethylene bags were collected from garbage. These were then cleaned with detergent and washed with water.All the biomass attached and the organic waste attached to the plastic was washed off. The plastic were then air dried and cut into small pieces. They were then grind in pestle mortar using crystalline $\mathrm{NaCl}$. Plastic was then washed with distilled water to remove all the salt and then was again air dried.

Table 1: Survey reports from city corporation office Belgaum

\begin{tabular}{|l|l|c|}
\hline \multicolumn{2}{|c|}{ Amount of plastic waste generated per day } & Weight \\
\hline \multirow{2}{*}{ Market area } & Plastic + moisture & $9.241 \mathrm{~kg}$ \\
\cline { 2 - 3 } & only plastic & $8.87 \mathrm{~kg}$ \\
\hline \multirow{2}{*}{ Residential area } & Plastic + moisture & $6.89 \mathrm{~kg}$ \\
\cline { 2 - 3 } & only plastic & $6.42 \mathrm{~kg}$ \\
\hline \multirow{2}{*}{ Commercial streets } & Plastic + moisture & $13.5 \mathrm{~kg}$ \\
\cline { 2 - 3 } & only plastic & $13.1 \mathrm{~kg}$ \\
\hline Total & & $\mathbf{2 8 . 3 9} \mathbf{~ k g}$ \\
\hline
\end{tabular}

\section{C) Pre-treatment of Plastic:}

1) UV treatment: Washed plastic were subjected to UV treatment in 3 ways. Firstly the plastic pieces were subjected to UV light in a simple cardboard box. The second way included the treatment in a mirror box. A mirror box was used to increase the reflection of UV light and hence enhance the amount of degradation. The third way included the use of steel box the objective being the same that is to increase the effect of UV on the plastic and hence enhance the degradation. The time of UV exposure was 3 days.(Ranby-1989, Nagai Y-2005, Abadal M-2006, Martin JW2003, Jensen-2003).

2) Nitric Acid treatment: The plastic pieces were dipped into concentrated Nitric Acid and kept in hot air oven at $35-37{ }^{\circ} \mathrm{C}$ and kept for a period of 6 days. (Arkatkar-2009, Artham-2008)

3) Thermal treatment: The plastic pieces were kept in hot air oven at a temperature of 100 ${ }^{\circ} \mathrm{C}$ for 2 hours. (Tayler DR-2004, Teare
DOH-2000, Goodings EP-1961, Ramis X2004)

4) UV + Nitric acid: Firstly the plastic were treated with UV then they were subjected to nitric acid treatment. The time of exposure being 3 days and 6 days respectively.

D) Use of different media for the growth of fungi: Three different types of media were used. In phase 1 media -the standard YPD (Yeast peptone dextrose) media was modified by replacing dextrose by plastic as the sole carbon source. In the phase 2 media, the standard media was modified by adding very little quantity of dextrose and peptone along with plastic carbon source. The main intention of adjusting the media constituents in such way was to divert the organism to feed on plastic so that the consumption of plastic would be more when compared to other media constituents. The third media contained $0.35 \%$ of cane molasses along with plastic as the carbon source. 


\section{E) Analysis methods for degradation of plastic:}

1) Dry weight analysis: After incubation period of 15 and 30 days, the remaining plastic was taken out of the media, air dried and then weighed again.

2) FTIR analysis: FTIR (Fourier transform infrared ray) analysis was done at RMRCICMR, Belgaum. The FTIR graph of treated plastic was compared with FTIR of standard plastic.

F) Pretreatment optimization: Out of the different pretreatment methods employed, the combination of UV + Nitric acid gave the better results. Thus this combination was further optimized by using different combinations of time used to expose the plastic to UV and Nitric acid.

\section{Results and Discussion}

A) Microorganism and media: The ordered organism was sub-cultured and maintained on PDA slants for further use.

B) Collection and cleaning of plastic: The plastic was collected and cleaned and thus was made into pieces for further treatment.

C) Pre-treatment of plastic: The pieces of plastic which were cleaned were now subjected to various pretreatment methods as per the procedure mentioned above.

D) Use of different media for the growth of fungi: As the different media were used to grow the fungi effectively with plastic being the carbon source in all the media, it was found that phase 3 media was very effective for the growth.

E) Analysis methods for degradation of plastic: Dry weight analysis: To confirm the degradation of plastic, the initial dry weight of the plastic was measured as $300 \mathrm{mg}$ which was then added into the media. After the incubation period was over, the remaining plastic was taken out of the media and was air dried till all the moisture was removed and the dry weight was once again measured and tabulated.From the results obtained, it can be clearly seen that the UV + Nitric acid treatment along with phase 3 media is best suited for degradation process. (Table 2)

2) FTIR analysis: standard: The FITR graph of standard plastic without any pre-treatment showed transmittance of around $43 \%$ at 2915.38 , $53 \%$ at $2847.72,80 \%$ at $1461.84,75 \%$ at 729.83 $\& 88 \%$ at 718.64 per $\mathrm{cm}$ wave numbers. (Fig 1)

Simple UV treated:The FTIR graph of simple UV treated plastic showed transmittance by sample 1 plastic around $40 \%$ at 2916.26, 46\% at $2858.5070 \%$ at 1472.04 and $1462.34,75 \%$ at 730.08 and $85 \%$ at 718.58 per $\mathrm{cm}$ wave numbers. As indicated in the picture there is an addition of an extra peak at 1472.04 per $\mathrm{cm}$. This extra peak may be due to the action of UV light on the plastic surface. Thus this addition is a proof to say that there is some structural change that has occurred in the polymer which is a sign of degradation. However there is not much of a change from the standard graph. (fig 2)

Nitric acid treated: The FTIR graph of nitric acid treated plastic showed transmittance by sample 2 plastic, around $78 \%$ at $2914.58,80 \%$ at $2847.06,85 \%$ at $1471.97 \& 1461.52,83 \%$ at $729.82 \& 93 \%$ at 718.74 per $\mathrm{cm}$ wave numbers. As indicated in this picture, there is an increase in the percentage of transmission at 2914.58 and 2847.06 to around $80 \%$ from a usual $40 \%$ in case of standard sample. Also there is an addition of extra functional group at 1471.97 per $\mathrm{cm}$.

The increase in transmission is due to decrease in number of C-C bonds. According to the principle of FTIR more the number of bonds, more is the absorption and less is the transmission and also more amount of energy is required is to cause the vibration of the bonds. Thus increase in transmittance suggests that the number of $\mathrm{C}-\mathrm{C}$ bonds have been decreased which is a definite proof of degradation. (fig 3). 
Kittur et al.

Table 2: The resulted decrease in the dry weight of the plastic

\begin{tabular}{|c|c|c|c|c|c|}
\hline $\begin{array}{l}\text { Sl. } \\
\text { No. }\end{array}$ & $\begin{array}{c}\text { PRETREATMENT } \\
\text { METHODS } \\
\text { along with media used }\end{array}$ & $\begin{array}{c}\text { INCUBATION } \\
\text { TIME } \\
\text { (IN DAYS) }\end{array}$ & $\begin{array}{l}\text { INITIAL DRY } \\
\text { WEIGHT } \\
(\mathbf{m g})\end{array}$ & $\begin{array}{l}\text { FINAL DRY } \\
\text { WEIGHT } \\
(\mathbf{m g})\end{array}$ & $\begin{array}{c}\% \\
\text { Degradation }\end{array}$ \\
\hline \multirow[t]{2}{*}{1.} & \multirow{2}{*}{$\begin{array}{c}\text { Simple UV } \\
\text { (Phase I media) }\end{array}$} & 15 & 300 & 293 & 2.33 \\
\hline & & 30 & 300 & 263 & 12.33 \\
\hline \multirow[t]{2}{*}{2.} & \multirow{2}{*}{$\begin{array}{l}\text { Specialized UV } \\
\text { (mirror box) } \\
\text { (Phase 1media) }\end{array}$} & 15 & 300 & 298 & 0.66 \\
\hline & & 30 & 300 & - & - \\
\hline \multirow[t]{2}{*}{3.} & \multirow{2}{*}{$\begin{array}{l}\text { Specialized UV } \\
\text { (steel box) } \\
\text { (Phase } 2 \text { media) }\end{array}$} & 15 & 300 & 292 & 2.66 \\
\hline & & 30 & 300 & 262 & 12.66 \\
\hline \multirow[t]{2}{*}{4.} & \multirow{2}{*}{$\begin{array}{c}\text { Nitric Acid } \\
\text { (Phase } 2 \text { media) }\end{array}$} & 15 & 300 & 267 & 11 \\
\hline & & 30 & 300 & 248 & 17.33 \\
\hline \multirow[t]{2}{*}{5.} & \multirow{2}{*}{$\begin{array}{c}\text { Nitric }+ \text { UV } \\
\text { (Phase } 2 \text { media) }\end{array}$} & 15 & 300 & 248 & 17.33 \\
\hline & & 30 & 300 & 221 & 26.33 \\
\hline 6. & $\begin{array}{c}\text { Thermal } \\
\text { (Phase } 2 \text { media) }\end{array}$ & 30 & 300 & 293 & 2.33 \\
\hline \multirow[t]{2}{*}{7.} & \multirow{2}{*}{$\begin{array}{l}\text { UV + Nitric acid } \\
\text { (Phase } 3 \text { media) }\end{array}$} & 15 & 300 & 243 & 19 \\
\hline & & 30 & 300 & 218 & 27.33 \\
\hline
\end{tabular}

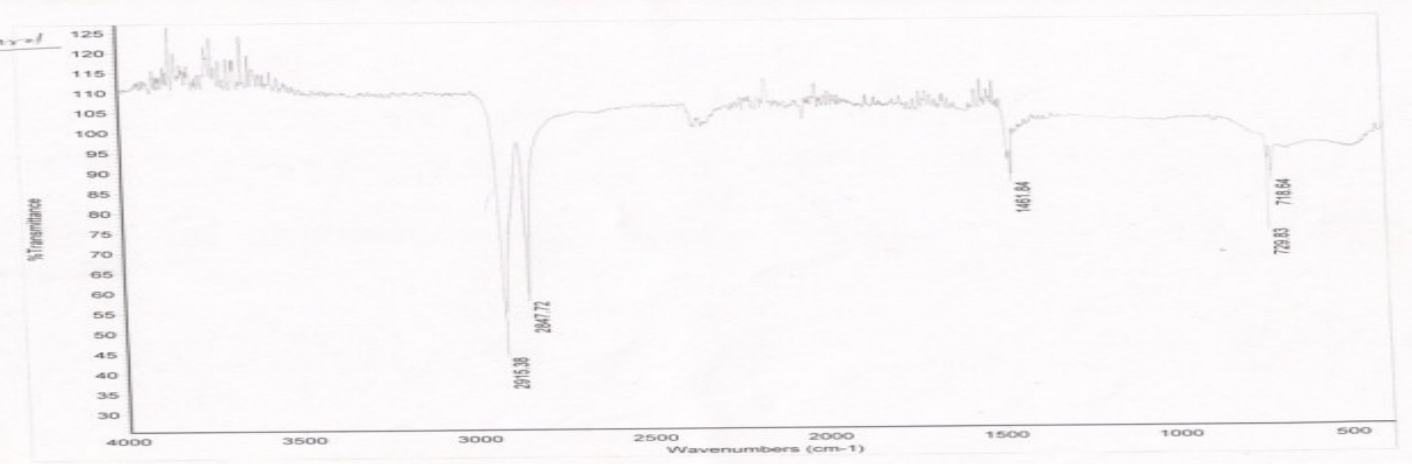

Fig 1: Standard sample

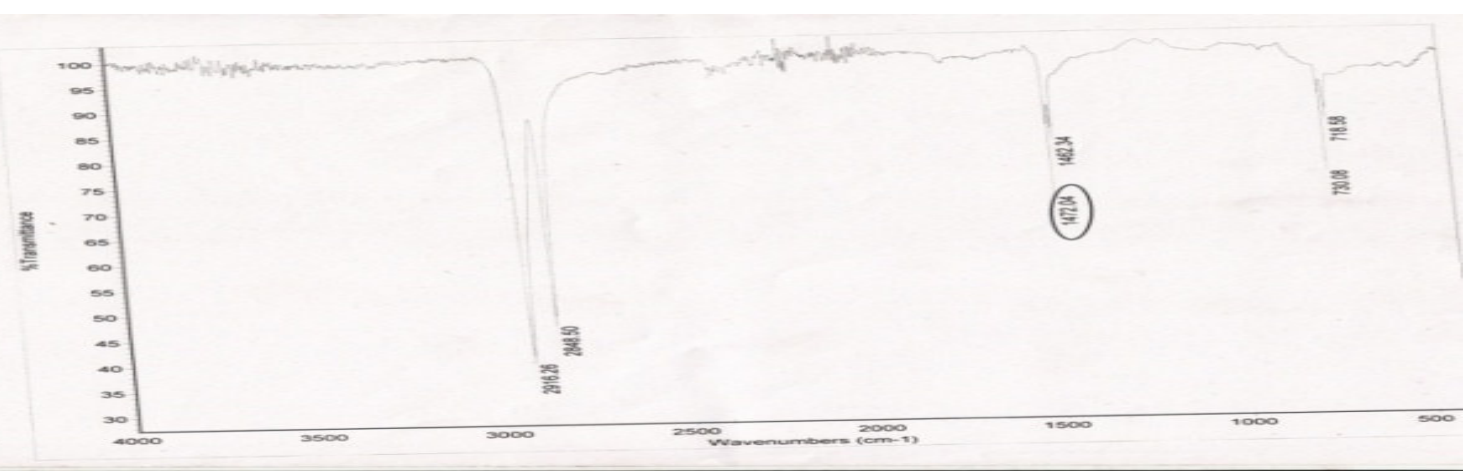

Fig 2: Simple UV treated

Environment Conservation Journal 


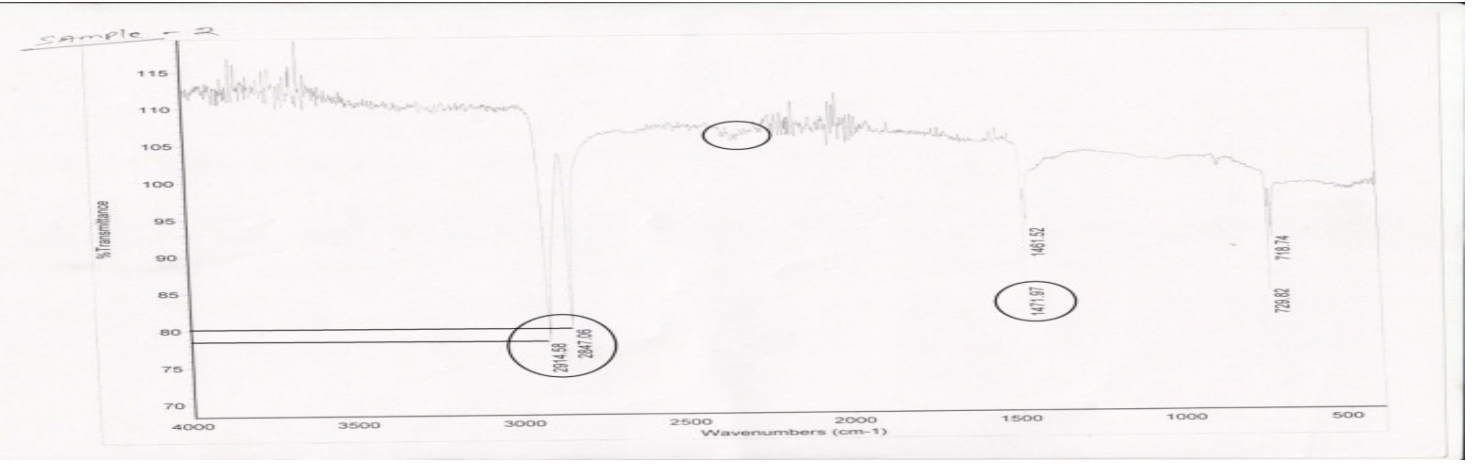

Fig 3: Nitric acid treated

Steel box UV: The FTIR graph of steel box UV treated plastic showed transmittance by sample 3 plastic around $68 \%$ at $2914.30,70 \%$ at 2846.98 , $87 \%$ at 1481.68 wave numbers. Even in this case as indicated in the picture there is increase in transmittance, thus it can be said that the plastic is been degraded to some extent. (fig 4)

UV + Nitric acid treated: The FTIR graph of $\mathrm{UV}+$ nitric acid treated plastic showed transmittance by sample 4, around $58 \%$ at $2914.93,61 \%$ at $2847.43,76 \%$ at $1471.42,88 \%$ at $1461.78,77 \%$ at $730.01, \& 88 \%$ at 718.63 wave numbers. The results in this particular sample are almost same as in case of sample number 2. But the results here are better when compared to the sample 2 because the sample that was tested using FTIR was of only 15 days and sample 2 was of 30 days. (fig 5)

Thermal treated: The FTIR graph of thermal treated plastic showed the transmittance of around $35 \%$ at $2915.27,48 \%$ at $2847.65,70 \%$ at $1471.94,82 \%$ at $1462.01,85 \%$ at 718.82 per $\mathrm{cm}$ wave numbers. There is not much of a change in transmittance in this case. As indicated in the picture, there is a few minute changes in the peaks in between 1700 and 2700 per $\mathrm{cm}$ of wave numbers. There is an addition of a functional group in the area of 1471.94 per $\mathrm{cm}$. Thus there is not much change as compared to the standard sample. Thus this treatment is not so effective. (fig 6)

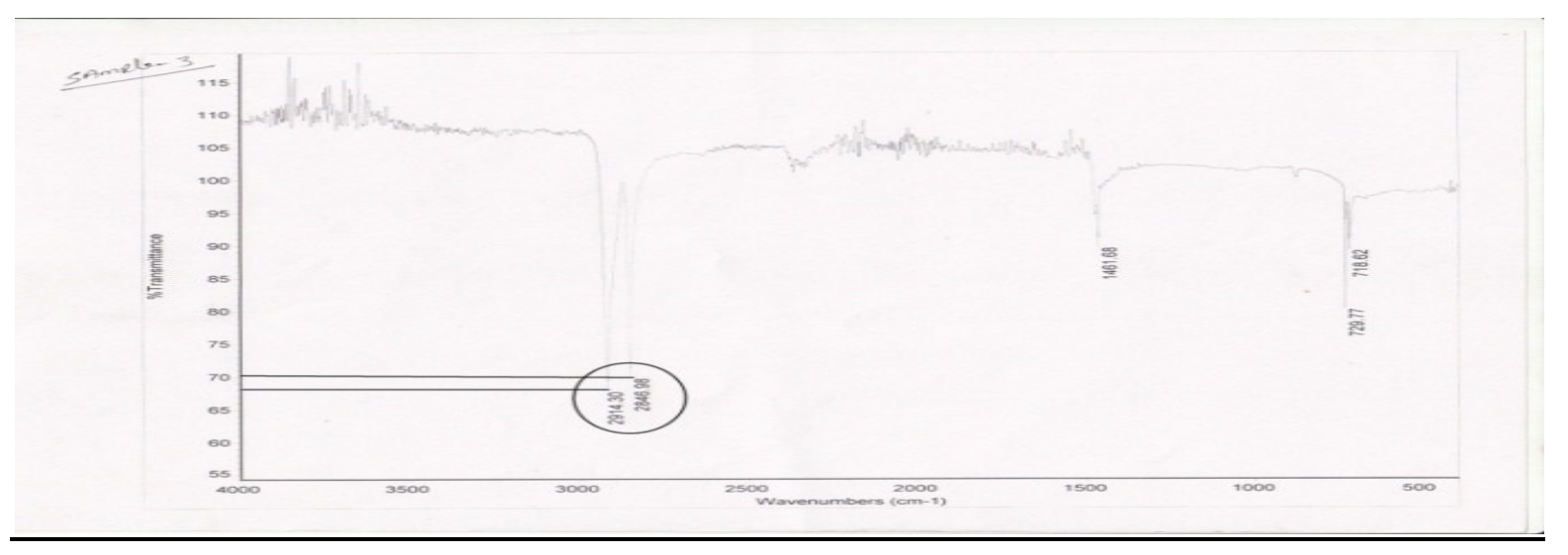

Fig 4: Steel box UV 


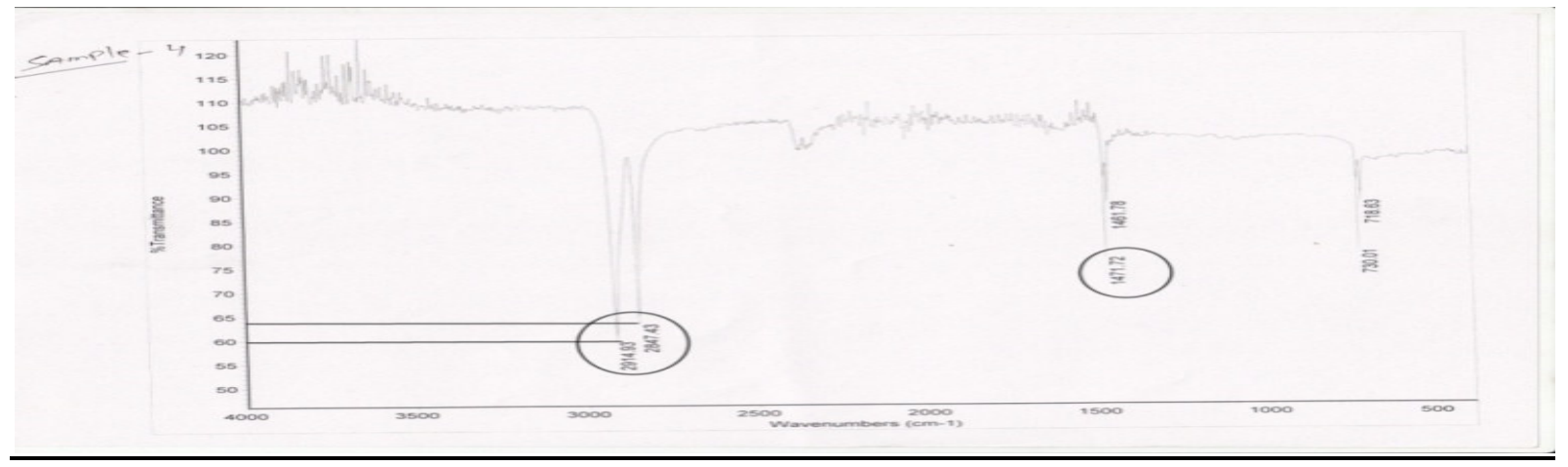

Fig 5: UV + Nitric acid treated

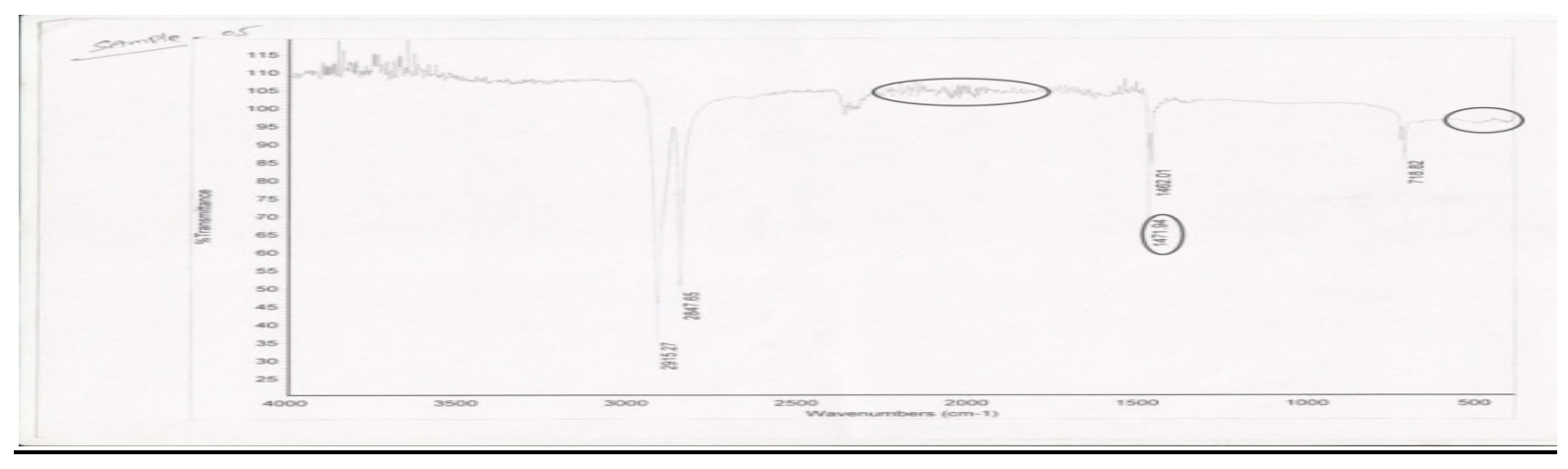

Fig 6: Thermal treated

$\underline{\mathrm{UV}}+$ Nitric acid in combination with molasses media:

The FTIR graph of UV + nitric acid treated in combination with molasses media plastic showed transmittance by sample 6 plastic, around $65 \%$ at $2915.21,75 \%$ at $2847.55,93 \%$ at $1461.82,98 \%$ at $1219.14,83 \%$ at $729.87,93 \%$ at 718.85 per $\mathrm{cm}$ wave numbers. As indicated in the picture, this particular pre-treatment with the combination of molasses media has shown a lot of changes in the polymer structure.
There is increase in transmittance from $40 \%$ in standard to around $77 \%$ in this case. Also there are two different functional groups that are introduced at1219.14 per $\mathrm{cm}$ and 1084.22 per $\mathrm{cm}$ wave numbers. The dry weight analysis of this particular sample also has given very good results when compared to other methods. Thus this particular combination of pre-treatment method and media is well suited for the process of degradation. Best degradation was seen in this case. (fig 7)

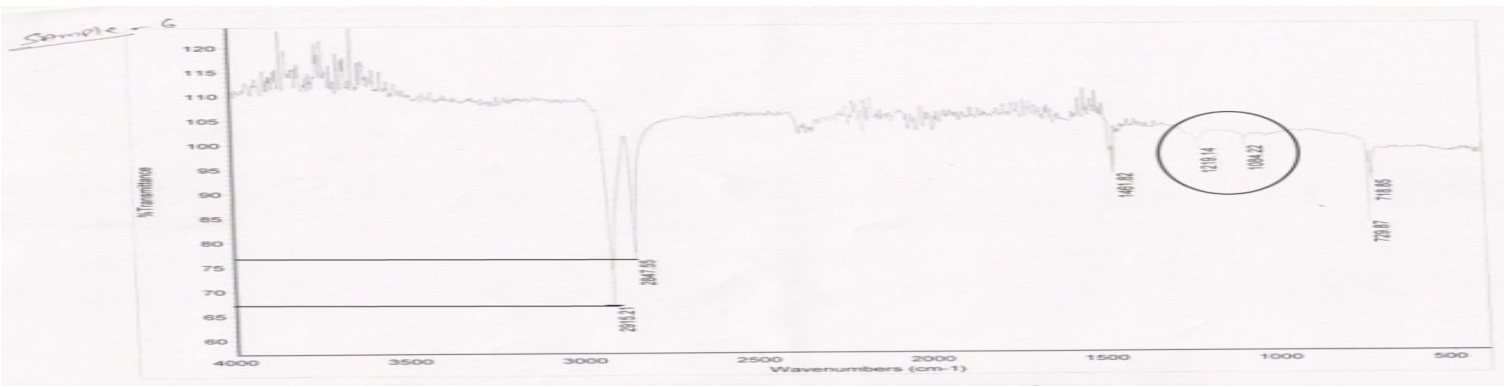

Fig 7: UV + Nitric acid in combination with molasses media 
From the FTIR analysis of all the samples it can be confirmed that the pretreatment method of plastic with UV+Nitric acid combination is the best suited when used along with phase 3 media.

F) Pretreatment Optimization (Table 3): The plastic was exposed to UV and Nitric acid at different combinations (as shown in the table) and then it was added as a carbon source into the phase 3 media.
It was then incubated with the organism for 15 days.

Later the dry weight of the remaining plastic was taken which showed that equal amount of exposure of both the pretreatment methods is necessary for better degradation. As seen from the table, the exposure time of 4 days of UV and 5 days of Nitric acid treatment was found to be more effective combination when compared to other combinations.

Table 3: Resulted decrease by pre-treatment optimization

\begin{tabular}{|c|c|c|c|}
\hline UV treatment(days) & $\begin{array}{c}\text { Nitric acid treatment } \\
\text { (days) }\end{array}$ & Total (days) & \% of degradation \\
\hline 1 & 8 & 9 & 2 \\
\hline 2 & 7 & 9 & 12 \\
\hline 4 & 5 & 9 & 24 \\
\hline 5 & 4 & 9 & 10 \\
\hline 6 & 3 & 9 & 11.25 \\
\hline 7 & 2 & 9 & 11 \\
\hline 8 & 1 & 9 & 6 \\
\hline
\end{tabular}

\section{Conclusion}

The results obtained from the various experiments that are carried out in the project conclude that Bio-degradation of the 40 micron polyethylene bag is possible with fungi Aspergillus niger. By constructing the biomass calibration curve, the effective growth of the fungi in PEG (Polyethylene glycol) media was calculated which showed a good growth which means that the organism can survive with polyethylene as carbon source considering + or $10 \%$ error as glycol is present as additional source of carbon along with polyethylene in PEG media. Testing the growth of fungi in different media like phase 1 , phase 2 and phase 3 , it was found that the phase 3 media (molasses media) is best suited for the growth of the fungus and also the degradation of plastic was good in case of molasses when compared to other media. Among the various pre-treatment methods that were used to treat the plastic, the combination of $\mathrm{UV}+$ nitric acid was found to be the best which gave 27.33\% degradation in 30 days in Phase 3 media.
Thus it can be concluded that large scale degradation process can be carried out in molasses media which is economical. The optimization of the pre-treatment methods indicated that the time of exposure of the plastic to UV and nitric acid should be in the range of 4:5days (UV: Nitric acid).

\section{Reference}

Abadal. M., Cermak, R., Raab, M., Verney, V. 2006. Commereuc S, Fraisse F. Study on photo degradation of injection moulded (beta)-polypropylene. Polym Degrad Stab 91(3):459e63.

Arkatkar, A., Arutchelvi, J., Bhaduri, S., Uppara, P. V., Doble, M. 2009. Int. Biodeterior.Biodegrad.63, 106111.

Artham, T., Doble, M. 2008. Macromo l.Biosci., 8 (1), 14-2

Goodings, E.P. 1961.Soc Chem Ind (London) Monogr $13: 211$

Hamid, S.H., Amin, M.B., Maadhah, A.G. 1995. Weathering degradation of polyethylene. In: Hamid SH, Amin MB, Maadhah AG, editors. Handbook of polymer degradation. New York: Marcel Dekker. 


\section{Kittur et al.}

Joel, F.R. 1995. Polymer Science \& Technology: Introduction to polymer science,Eds. 3, Pub: Prentice Hall PTR Inc., Upper Saddle River, New Jersey 07458, p: 4-9.

Jensen, J.P.T., Kops. J. 2003. Photochemical degradation of blends of polystyrene and poly (2, 6-dimethyl-1,4phenylene oxide). J Polym Sci Polym Chem, 18 (8):2737e46.

Mark, H.F., Bikales, N.M., Overberger, C.G., Menges, G. 1986. Encyclopedia of polymer science and engineering.2nd ed., vol. 4. New York: Wiley Interscience Publication; p. 630e96.

Martin, J.W., Chin, J.W., Nguyen, T. 2003. Reciprocity law experiments in polymeric photodegradation: a critical review. Prog Organic Coatings , 47:292e311.

Nagai, Y., Nakamura, D., Miyake, T., Ueno, H., Matsumoto, N., Kaji, A. 2005. Photodegradation mechanisms in poly (2,6-butylenenaphthalate-cotetra methylene glycol) (PBNePTMG). I: Influence of the PTMG content. Polym Degrad Stab, 88(2):251e5.
Ranby, B. 1989. Photodegradation and photo-oxidation of synthetic polymers. J Anal Appl Pyrolysis ,15:237e47.

Ramis, X., Cadenato, A., Salla, J.M., Morancho, J.M., Valles, A., Contat, L., 2004. Thermal degradation of polypropylene/starch-based materials with enhanced biodegradability. PolymDegrad Stab, 86:483e91.

Scott, G. 1990. Photo-biodegradable plastics: their role in the protection of the environment. Polym Degrad Stab ,29:135-54.

Tayler, D.R. 2004. Mechanistic aspects of the effect of stress on the rate of photochemical degradation reactions in polymers. J Macro mol Sci Part C Polym Rev ,44(4):351e88.

Teare, D.O.H., Emmison, N., Tonthat, C., Bradley, R.H. 2000. Cellular attachment to UVozone modified polystyrene surfaces. Langmuir, 16(6):2818e24.

Zuev, V.V., Bertini, F., Audisio, G. 2006. Investigation on the thermal degradation of acrylic polymers with fluorinated side-chains. Polym Degrad Stab , 91 (3): 512 e6. 